\title{
Supporting collaborative reflection in teacher education: a case study
}

\section{Marc Clarà, Teresa Mauri, Rosa Colomina \& Javier Onrubia}

To cite this article: Marc Clarà, Teresa Mauri, Rosa Colomina \& Javier Onrubia (2019): Supporting collaborative reflection in teacher education: a case study, European Journal of Teacher Education, DOI: $10.1080 / 02619768.2019 .1576626$

To link to this article: https://doi.org/10.1080/02619768.2019.1576626

曲 Published online: 06 Feb 2019.

Submit your article to this journal

山 Article views: 36

View Crossmark data $[\pi$ 


\title{
Supporting collaborative reflection in teacher education: a case study
}

\author{
Marc Claràa, Teresa Maurib, Rosa Colomina ${ }^{\mathrm{b}}$ and Javier Onrubiab \\ aDepartment of Pedagogy and Psychology, University of Lleida, Lleida, Spain; bepartment of Cognition, \\ Development and Educational Psychology, University of Barcelona, Barcelona, Spain
}

\begin{abstract}
The aim of this paper is to understand how certain educational supports promote preservice teachers' learning to reflect in collaborative settings. To address this issue, we present a case study on collaborative reflection among 14 preservice teachers and one teacher educator over the course of five weekly consecutive sessions. The results suggest that collaborative reflection can be supported by organizing the process according to a twofold dynamic: from analysis to synthesis, and from open facilitation to directive facilitation. Six different types of assistance related to this dynamic, and provided by the teacher educator, are identified and qualitatively described: framing, oppositional voice, counterpoising alternatives, asking for the dilemma, problematizing, and modelling.
\end{abstract}

\section{ARTICLE HISTORY}

Received 24 January 2018 Accepted 25 January 2019

\section{KEYWORDS}

Preservice teacher education; reflective practice; teacher educators

Today reflection lies at the very core of many teacher education programs around the world (Buschor and Kamm 2015; Korthagen 2001; Postholm 2008; Jarvis et al. 2014). However, reflection in teacher education still remains more a promise than a reality. Many critiques and doubts have been expressed in relation to both the concept of reflection and its central role in teacher education (Collin, Karsenti, and Komis 2013; Mena-Marcos, Sanchez, and Tillema 2011). What all these critiques make clear is that for reflection to become the cornerstone of teaching, several challenges must be addressed and overcome. One of these challenges has to do with the observation that student teachers need assistance in order to learn to reflect. The question thus becomes how teacher education can best provide this assistance (Beauchamp 2015; Blomberg et al. 2014; Gelfuso and Dennis 2014; Liu 2017). This paper contributes to this challenge by means of a case study on collaborative reflection conducted over the course of 5 weekly sessions between a teacher educator and 14 preservice teachers who were in the process of completing practicums at different schools. The study proposes three research questions: 1) how did student teachers' reflection progress over the course of the five weeks; 2 ) how did the social organization of the collaboration contribute to this progress; and 3) how did the assistance provided by the teacher educator contribute to this progress.

CONTACT Marc Clarà $\otimes$ marc.clara@gmail.com E University of Lleida, Avinguda de l'Estudi General, 4, Lleida 25001, Spain 


\section{Theoretical framework}

In recent years, many authors have argued that collaborative reflection may be a good strategy to help student teachers learn to reflect (Daniel, Auhl, and Hastings 2013; Harford and MacRuaric, 2008; McCullagh 2012). However, research on the effectiveness of this strategy has yielded contradictory results. Some studies report that collaboration facilitates deeper critical reflection and knowledge construction (Attard 2012), pushes the level of reflection from describing to theorizing (Manouchehri et al., 2002), and helps student teachers engage with new ideas (Sorensen 2014). In contrast, other studies on collaborative reflection have found poor levels of problem understanding and perspective shift (Tillema and Van Der Westhuizen 2006), overly descriptive and poorly elaborated reflection (Wopereis, Sloep, and Poortman 2010; Killeavy and Moloney 2010), and poor use and integration of theory (Postholm 2008). In light of these contradictory findings, some authors have suggested that the success of collaborative reflection as a means to promote reflection among student teachers depends on two main aspects: how knowledgeable others (e.g., a teacher educator) assist with the process; and how collaboration is socially organized (Gelfuso and Dennis 2014; Korthagen 2001; MooreRusso and Wilsey 2014).

Several studies have looked at assistance by knowledgeable others. For example, Foong, Nor, and Nolan (2018) draw a continuum of facilitation styles: at one end of the continuum there is facilitation based on asking open-ended questions and letting the students speak freely, without trying to directly influence or change students' ideas. At the opposite end of the continuum, facilitation is based on demonstration; that is, the facilitator directly conducts reflection, so that students can observe and imitate. In between these two ends, Foong, Nor, and Nolan (2018) establish four reference points to characterize the facilitation styles: from more open to more directive, these are called collaborator, coach, navigator, and master. These authors suggest that more open facilitation styles foster deeper levels of reflection by students. Kim and Silver (2016) also consider the importance of open facilitation, but their results suggest that deeper reflection may be better promoted if open facilitation is used in the beginning of the reflective process, and then more directive facilitation is progressively introduced. This finding is coherent with the observations and concerns of Liu (2017). Grounded in the works of Bakhtin and Mezirow, Liu understands that reflection involves dialogue between different real or imagined voices. Thus, the main potentiality of social collaboration for reflection is that it introduces multiple social voices into the reflection process. However, according to Liu, reflection requires the interrelation between these multiple voices, not only the examination of each of them in isolation. In her study of three cases, Liu (2017) shows that different and conflicting voices are present in collaborative reflection but that these voices are not interrelated. According to the author, this is due to a lack of follow-up and directedness by the facilitator, leading to missed opportunities for promoting deeper reflection. These findings suggest that open facilitation may be necessary to permit the emergence of different voices, but also that more directive facilitation may be necessary to make these voices converge and engage in dialogue with each other.

The transition, suggested by Liu, from the multiplicity of (isolated) voices toward the interrelation between voices, echoes Dewey's idea, especially emphasized in the 1910 
version of 'How we think' (Dewey [1910] 1978), that reflection involves a movement from analysis to synthesis. ${ }^{1}$ This aspect is central in some recent models for the social organization of collaborative reflection, such as in Gelfuso (2016). In fact, there are several proposed models to organize collaborative reflection, involving different successive phases as well as different specific facilitation strategies (e.g., Behizadeh, Thomas, and Cross 2017; Korthagen 2001; Tigelaar et al. 2008; Liu 2015; Gelfuso 2016). However, these models are usually prescriptive, that is, deductively proposed, and since they depart from different theoretical grounds, as well as from different understandings of what reflection is and is for, the different models are hardly commensurable. Nevertheless, beyond specific models, two social aspects have been recurrently found to be important for successful collaborative reflection. Firstly, it seems to be crucial that the participants share an aligned idea of what the aim and the discursive rules of collaborative reflection are (Alles, Seidel, and Gröschner 2018; Attard 2012; Tillema and Van Der Westhuizen 2006; Yoon and Kim 2009). Secondly, it seems to be vital to generate an environment of trust and confidence among the participants (Alles, Seidel, and Gröschner 2018; Attard 2012; Postholm 2008; Wopereis, Sloep, and Poortman 2010).

The important divergences among the different proposed models of collaborative reflection resonate with some critiques about the ambiguity of the concept of reflection (Beauchamp 2015; Collin, Karsenti, and Komis 2013) and with the observation that different scholars and teacher educators may have different views on the purposes and priorities of reflection (Korthagen 2001; Mansvelder-Longayroux, Beijaard, and Verloop 2007). In this regard, the literature on teacher education refers to at least three forms of reflection. First, some researchers and teacher educators understand reflection as linking (or generating) theoretical propositions with (or from) a situation of practice (Gelfuso 2016; Korthagen 2001; Moore-Russo and Wilsey 2014; Postholm 2008). Second, some authors understand reflection in terms of critically considering political interests, power relations, and ethical and moral issues involved in a situation of practice (Daniel, Auhl, and Hastings 2013; Harford and MacRuairc 2008; Land 2018; Liu 2015). Third, still others understand reflection in terms of identifying and understanding the dilemmas and tensions that give rise to a situation of practice (Cochran-Smith and Demers 2010; Lampert 1985; Yoon and Kim 2009). In this paper, we assume a pluralistic stance about the purpose of reflection: although we assume that reflection necessarily involves a process of clarification of an initially unclear situation (Clarà 2015), we also assume that there are multiple paths for bringing clarity to the situation. Therefore, we sustain that the paths followed in a given reflection process must be considered according to the kind of clarity this process is looking for, such as theoretical, critical, or dilemmatic clarity. Although the different types of clarity are not incompatible, it may be useful to distinguish between them in order to adequately understand the support systems in relation to the form of reflection each system seeks to promote. In the case we analyse below, the type of clarity sought in reflection was dilemmatic.

\section{Method}

\section{Participants and setting}

This paper reports a case study about collaborative reflection involving one teacher educator (member of the research team) and 14 preservice teachers in Catalonia (Spain). 
The preservice teachers, who were in the third year of a four-year teaching degree program, were completing a three-month practicum at different schools. Throughout the three months of the practicum, they spent four days a week, full time, at their schools and, on the fifth day, met at the university with the teacher educator and reflected together about specific situations they had experienced at their respective schools. These situations were selected, written up and presented by the preservice teachers themselves.

The teacher educator had two years of previous experience with teaching practicums. He also worked at the university as a lecturer of educational psychology and had conducted research about teacher knowledge and teacher reflection. In an interview conducted after the five reflection sessions (but before the beginning of the analysis), he stated that he had not followed any specific model of reflection. His main concerns regarding his facilitation role had been: a) promoting dialogue among the student teachers; and $b$ ) that the reflection process advance to somewhere. In his years of previous experience with practicums, he had worked with these same two concerns in mind. When asked about the purpose of the reflection processes that he had facilitated, he stated that his objective was to promote, in the students, a dialectical understanding of the situations, in terms of dilemmas.

\section{Data gathering and analysis}

Once the informed consent of all the participants had been obtained, the first five collaborative reflection sessions were videotaped. Atlas.ti 7 software was used to conduct three different analyses, in subsequent steps. First, interactivity analysis (Coll, Onrubia, and Mauri 2008) was used to understand the social organization of the collaborative reflection. This analysis was based on inductively identifying different structures of participation (Erickson and Schulz 1997). Codes were then generated for each of the identified structures in order to characterize the pattern of interaction among participants and what the participants were doing together. Inter-rater reliability was calculated, resulting in a Cohen's Kappa of $K=.935$. Second, content analysis (Krippendorff 1980) was used to understand how the participants reflected. To this end, four broad categories (based on Clarà 2015) were deductively established (Table 1). Inter-rater reliability was $K=.917$.

Finally, inductive procedures (Strauss and Corbin 1990) were used to understand the nature and functions of the teacher educator's interventions with regard to supporting preservice teachers in the process of learning to reflect. This interpretative analysis was based on a detailed and iterative examination of the raw data. Codes and memos were generated for the teacher educator's turns, with close consideration of the discursive context. These codes and memos were then iteratively developed by systematically comparing them with other codes and memos, similarly generated from the teacher educator's previous and subsequent turns.

Since the teacher educator was a member of the research team, he was excluded from the coding process of the two first analyses, which were conducted by the other members. Once the data had been coded, he participated, together with the other members, in the third analysis and the global interpretation of the results.

In addition to the videotaped data, once the five sessions had been finished, a questionnaire was administrated to preservice teachers and an interview was conducted with the teacher educator; both the questionnaires and the interview were used as complementary data. 
Table 1. Content analysis scheme for reflection.

\begin{tabular}{|c|c|c|}
\hline Category & Description & Example \\
\hline Problematizing & $\begin{array}{l}\text { Participants refer to an incoherence or problem } \\
\text { in the situation or provide arguments for or } \\
\text { against the existence of that incoherence or } \\
\text { problem in the situation }\end{array}$ & $\begin{array}{l}\text { “...but the thing is, there are two older sisters } \\
\text { who studied in Catalan, who studied at the } \\
\text { same school, and the parents didn't have any } \\
\text { problems with that, and now, suddenly, } \\
\text { another child comes along, and they have this } \\
\text { about-face, you know? I mean, that's what } \\
\text { I can't, what I don't understand, why, you } \\
\text { know? (student, Session 4, Situation F) }\end{array}$ \\
\hline Action & $\begin{array}{l}\text { Participants propose alternative ways of action } \\
\text { to deal with the situation or provide } \\
\text { arguments for or against the adequacy of } \\
\text { these actions }\end{array}$ & $\begin{array}{l}\text { '...so if she's been unhappy with how the school } \\
\text { works for that long, she should switch schools' } \\
\text { (student, Session 1, Situation A) } \\
\text { '...I don't know, first explain to her why you're } \\
\text { doing it, I mean, tell the mother, explain to } \\
\text { her why they're doing all that' (student, } \\
\text { Session 1, Situation A) }\end{array}$ \\
\hline Explanation & $\begin{array}{l}\text { Participants propose a way of understanding the } \\
\text { situation that gives it coherence or provide } \\
\text { arguments for or against the plausibility of } \\
\text { this explanation }\end{array}$ & $\begin{array}{l}\text { 'maybe her methodology recommends, or she } \\
\text { sees that the way they do their activities is an } \\
\text { approach in which the teacher is there more } \\
\text { to provide support, and that the children work } \\
\text { in a certain way, etc., etc., and that doesn't } \\
\text { work with her group' (student, Session 5, } \\
\text { Situation G) }\end{array}$ \\
\hline Evaluation & $\begin{array}{l}\text { Participants make value judgments (political, } \\
\text { moral, ethical, etc.) about the situation or } \\
\text { provide arguments for or against the fairness } \\
\text { of these judgments }\end{array}$ & $\begin{array}{l}\text { '... if the tone is questioning the teacher, and } \\
\text { with that whole "my child didn't understand } \\
\text { and..." thing, I don't think that's the right way } \\
\text { to do it' (student, Session 1, Situation A) }\end{array}$ \\
\hline
\end{tabular}

\section{Results}

\section{Overview of the case}

Over the five collaborative reflection sessions, the teacher educator (TE) and the preservice teachers reflected on 8 different situations. The teacher educator had a clear and explicit idea of his purpose during the collaborative reflection, which he consistently explained over the course of the five sessions. Briefly, this purpose was threefold: to encourage the preservice teachers to explain the situation in terms of tensions or dilemmas; to prevent them from making value judgments; and to prevent them from trying to solve the situation through alternative actions.

TE: ... the idea behind this exercise with the situations is not to solve the situation, (...) it's not to give an opinion about the situation, it's not to make a judgment about the situation. The basic idea of this exercise is to try to consider the situation in depth, that is, not to stay on the surface. It is to try to understand the internal tensions of the situation, what elements are at play in the situation, ok? That's the idea.

(Session 4, Situation F)

The evolution of the preservice teachers' reflection at the five collaborative reflection sessions is shown in Figure 1:

As Figure 1 shows, while there was no clear trend in the evolution of Evaluation and Problematizing, Action quite clearly decreased, especially after Session 2, and Explanation increased, especially after Session 3. At the end of the five sessions, the preservice teachers were asked to answer an anonymous questionnaire, with the question of 'which specific issues would you highlight of what you have learned in this 
experience'. Several of them highlighted the idea of considering the tensions between multiple points of view and the importance of not judging or trying to solve the situation before carefully understanding what is happening:

PT1: The situations teach us to reflect without looking for solutions. It makes you see the different viewpoints of things

PT2: I learned to give more importance to all the factors that intervene in the different situations which can take place in class, that is, to be more reflexive and take more into account all the viewpoints. Also to relativize things and see that there are limits and we have to adapt to them.

PT3: To not be judgemental in the beginning. To think first in seeing the case from outside. To try to see the consequences that your decision has on a case.

PT4: To break with the ideas I had and reflect with a professional mentality. To try to analyse a situation before judging.

PT5: Putting on the shoes of the different 'characters' to understand better their situation

The trends in the evolution of preservice teachers' reflection, as showed in Figure 1, were clearly aligned with the teacher educator's purpose as described above, especially with the ideas of explaining the situation and avoiding trying to solve it through alternative actions. Besides, many of the responses to the questionnaire by the preservice teachers are in line with the teacher educator's idea of advancing toward dilemmatic understanding of the situations.

\section{Social organization of the collaborative reflection}

In this case, the collaborative reflection was socially organized in four general phases, here labelled Clarification, Exploration, Focalization, and Interpretation. In the first phase, the preservice teachers asked the peer who had presented the situation under reflection quick questions to request clarification or further information. In the Exploration phase, the preservice teachers openly and freely discussed different aspects of the situation (analysis). In the Focalization phase, the conversation was more strongly guided by the

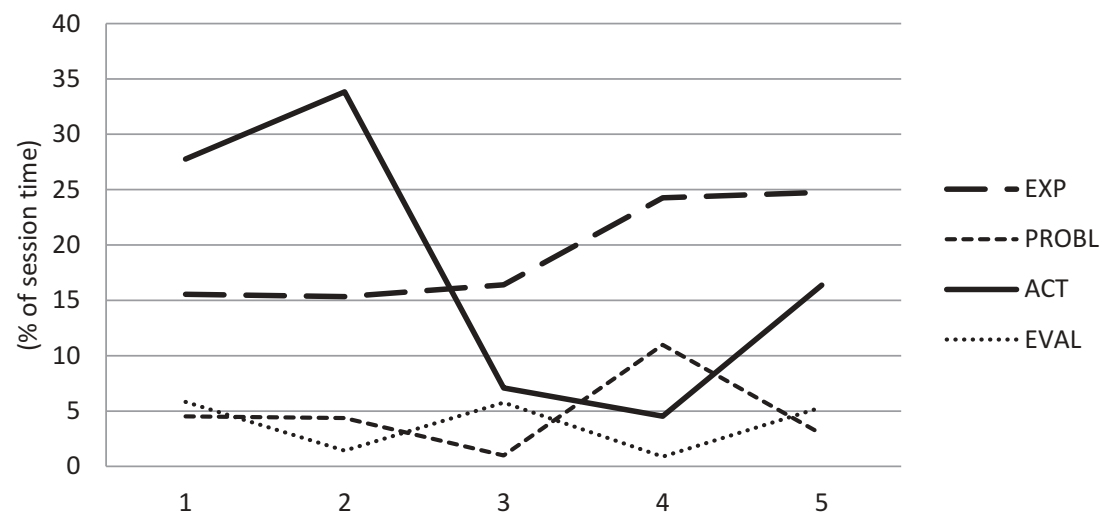

Figure 1. Evolution of the preservice teachers' reflection over the five collaborative reflection sessions. EXP: Explanation; PROBL: Problematizing; ACT: Action; EVAL: Evaluation. 
Table 2. Phases and time for each situation.

\begin{tabular}{lccccc}
\hline Session & Situation & Clarification & Exploration & Focalization & Interpretation \\
\hline 1 & A & No & $0: 16: 43$ & $0: 35: 32$ & No \\
& B & No & $0: 13: 16$ & $0: 12: 57$ & No \\
2 & C & $0: 02: 59$ & $0: 07: 36$ & $0: 07: 45$ & $0: 07: 19$ \\
& D & $0: 07: 29$ & $0: 03: 03$ & $0: 06: 35$ & $0: 04: 11$ \\
3 & E & No & $0: 07: 11$ & $0: 36: 22$ & $0: 09: 05$ \\
4 & F & $0: 06: 26$ & $0: 06: 48$ & $0: 14: 45$ & $0: 06: 09$ \\
5 & G & $0: 07: 27$ & No & $0: 09: 40$ & $0: 05: 55$ \\
& H & $0: 02: 58$ & $0: 04: 51$ & $0: 06: 20$ & $0: 05: 10$ \\
& Cumulated: & $0: 27: 19$ & $0: 59: 28$ & $2: 09: 56$ & $0: 37: 49$ \\
& $\%$ & 10,73 & 23,36 & 51,05 & 14,86 \\
\hline
\end{tabular}

teacher educator, although the interaction still had the structure of an open conversation. In this phase, the conversation was aimed at establishing contrasts and relationships between the different aspects explored by the preservice teachers in the previous phase (synthesis). In the Interpretation phase, the teacher educator provided an explanation of the situation. These four phases were quite consistent throughout the five sessions, although there were some variations (Table 2).

\section{Evolution of the teacher educator's assistance}

Our analysis suggests that the aim of the teacher educators' assistance shifted after Session 2. In the first two sessions, the assistance was mainly aimed at encouraging the preservice teachers to focus on explanation (instead of action); after the second session, the aim of the assistance shifted to improving the explanations the preservice teachers provided by further clarifying internal tensions and dilemmas. In keeping with these two main aims of the assistance, the teacher educator used different assistance strategies, which are explained in detail in the following sections.

\section{Encouraging an explanatory stance on reflection}

In the first two sessions, the TE's assistance seemed to pursue two main (complementary) objectives. On the one hand, he tried to balance the preservice teachers' views on the situation by ruling out premature assumptions that would eliminate the instability caused by the situation. He did this by means of two strategies, here called framing and oppositional voice. Framing consists of introducing assumptions into the situation in order to prevent preservice teachers from getting around the instability of the situation. Oppositional voice consists of arguing against the pervasive position taken by the preservice teachers. On the other hand, the TE pushed the preservice teachers to understand the dilemma(s) of the situation. In the first two sessions, he did this through a strategy here called counterpoising alternatives, which consists of calling the preservice teachers' attention to two opposed (balanced) possible actions.

Situation A concerned a mother who questions the pedagogical methods used by a teacher. In the conversation, the preservice teachers focused mainly on finding a solution for the situation, assuming that the mother was not acting the right way. 
20 Olga:... I mean, as a teacher, I would be indignant, because there's nothing you can do. You can't go after the mother, but you also can't get bogged down in fights, and you have to read her and think, 'Fine, if you don't like it, take the girl (somewhere else).' As long as the girl is here, (you have to) deal with it the best you can, without getting into a conflict with the mother, because obviously if you press this mother's buttons, she's going to cause trouble, you know? [...]

23 TE: Let's do something. We'll continue in a second. I'm just saying, let's suppose... let's think about Framing this situation (...), but supposing that the mother isn't doing this just to annoy the teacher, right?

24 Olga: Why then?

25 TE: Because she really has a certain view about her child's education, OK? Let's think about that, or rather (...), let's start with that assumption, OK?

As this excerpt shows, the preservice teachers assumed that the mother was looking for trouble (20). In 23-25, the TE used framing to rule out this assumption and introduce instead the assumption that the mother was really involved with and concerned about her child's education. Some turns later, the following dialogue occurred:

49 TE: OK, now l'd like to rephrase the question slightly, to say, let's not say... [...] let's avoid assessing who's right and who's wrong, and let's look at it as two opposing viewpoints, the... + let's say, the teacher's and the mother's, and my question is, which one should prevail?

David: The teacher's.

53 TE: Why?

54 David: In theory, she's the professional responsible for ensuring that the students learn certain skills and improve. For a mother not to be sure that the person responsible for her child's education is doing things right is like if I have to have some construction work done on my home, and I hire a construction worker that I know will do a bad job [...]

55 Judit: [...] but also, if the mother... let's imagine a case where the mother might, where she might be right [...].Maybe the teacher... we're not perfect, we make mistakes, and I think we need to know how to take criticism (...) take it as something constructive and improve. [...]

56 Elsa: But criticism has to be based on knowledge. I can't criticize how a construction worker does his job, because I can't do it. But if you're being questioned about something that has been analyzed based on knowledge or experience (...) that, where there is a basis for that knowledge. I can't judge people without having some idea...

In 49, the TE offered a new framing: he introduced the assumption that the mother's views on teaching were no less correct than the teacher's. Upon this assumption, the TE then asked the preservice teachers to examine the contradiction between the teacher's and mother's points of view and determine which view should prevail. This strategy is what we call counterpoising alternatives. In the following turns (52-56), an analogy was made with a construction worker and the person who hires that worker. This analogy was leading the preservice teachers to solve the counterposition via professional authority: education is the teacher's job, so her view should prevail. However, a few turns later, the TE introduced a counter-argument to this analogy. This strategy is what we call oppositional voice:

60 TE: She [Elsa] said, 'I can't give my view on building a wall if I can't do a construction worker's Oppositional job.' But is that a valid comparison? Think about it for a minute. Isn't the mother educating voice the child, too? The teacher is educating the child, and the mother is educating the child, right? Who is more responsible for the child's education? 
After this oppositional voice by the TE, the preservice teachers immediately sought to find solutions aimed at eliminating the conflict between the mother and the teacher, but the TE used framing to prevent the preservice teachers from side-stepping the opposition between the mother's and teacher's points of view:

63 Isabel: Maybe they should talk, I think. Maybe each one should give her opinion and reach...

64 TE: Sure. She's proposing a solution, right? It came up before: a meeting, right? But what Framing + I'm saying is no, let's not look for a specific solution because, sure, we could say, 'OK, let Contraposition them have a meeting and come to an agreement,' [...] What you're saying, the meeting, or what you're suggesting is to say, 'OK, so if there's a contradiction, let's try to make the contradiction disappear.' What I'm saying is, 'No, no, no. The contradiction exists, right? And in light of that contradiction, which viewpoint should prevail?' That's what I'm asking.

In 63, a preservice teacher proposed that the teacher and the mother meet and reach an agreement, so as to eliminate the opposition of points of view. In 64, the TE framed the situation by introducing the assumption that there is no way to eliminate the discrepancy between the mother and the teacher, so the preservice teachers cannot avoid the opposition of viewpoints. After the framing, the TE again counterpoised alternatives. The students finally did face the opposition, considering what would be gained and what would be lost if either of the positions prevailed. The following excerpt summarizes this exercise:

78 Lídia: I think if the mother's point of view prevails, and we give in, and we change how we do things, we'd lose confidence in ourselves and in our pedagogical approach and that would lead to confusion, because suddenly you wouldn't know what you're doing, I mean, you'd be straying off course, and that would mean having to change a lot of other things, and then you could get lost and cause a lot more students to get lost too, because you'd no longer be doing the (sure thing).

79 Laura: On the other hand, if the mother's opinion prevails, we might come out ahead, insofar as each teacher would reconsider whether or not they were doing a good job and reflect on their teaching practice, right? Reflection from the standpoint of improving and doing, trying to do positive things.

\section{Encouraging dilemmatic explanations}

The reflection on Situation $C^{2}$ (the first of Session 2) was qualitatively similar to those of Session 1. Basically, the TE tried to balance the preservice teachers' views of the situation by means of framing (less than in Session 1) and oppositional voice (more than in Session 1), before counterpoising alternatives. However, at the very end of Situation C, the TE began to shift the direction of his assistance. Once the alternatives had been counterpoised, the TE used, for the first time, a strategy here called asking for the dilemma. He then provided a model of what understanding the dilemma in the situation means (in fact, the introduction of this model explains the appearance of the Interpretation phase in the social organization of Situations ( to $\mathrm{H})$ : 
67 TE: What would you say is... the underlying dilemma in this situation, in other words, the Asking for the dilemma underlying the decision that needs to be made? What would you say it is? dilemma

68 David: Choosing whether the girl will get anything out of repeating sixth grade or if it is better for her to continue onto high school which is the...

69 Anna: Deciding what's best for her learning.

70 TE: What? Sorry?

71 Anna: Deciding what's best for her learning, (...) to learn more [2 seconds]

72 TE: I don't know. The way I see it is, I mean, the decision is sort of do we protect the girl? Modelling Or... In other words, do we protect the girl in a controlled environment? Or, from an educational point of view, do we also have the (responsibility) to, to make her leave somehow, right? leave this environment. I don't know, in my view, that's sort of the dilemma

Here, in 67 , the TE directly asked the preservice teachers to define the dilemma. After a few tentative attempts by the preservice teachers, he provided a definition himself (72), which thus became a model of what he was asking for when he asked for the dilemma. Immediately thereafter, Situation $\mathrm{D}^{3}$ began, and when the TE intervened, he did not devote much time to counterpoising alternatives, but rather almost directly asked for the dilemma.

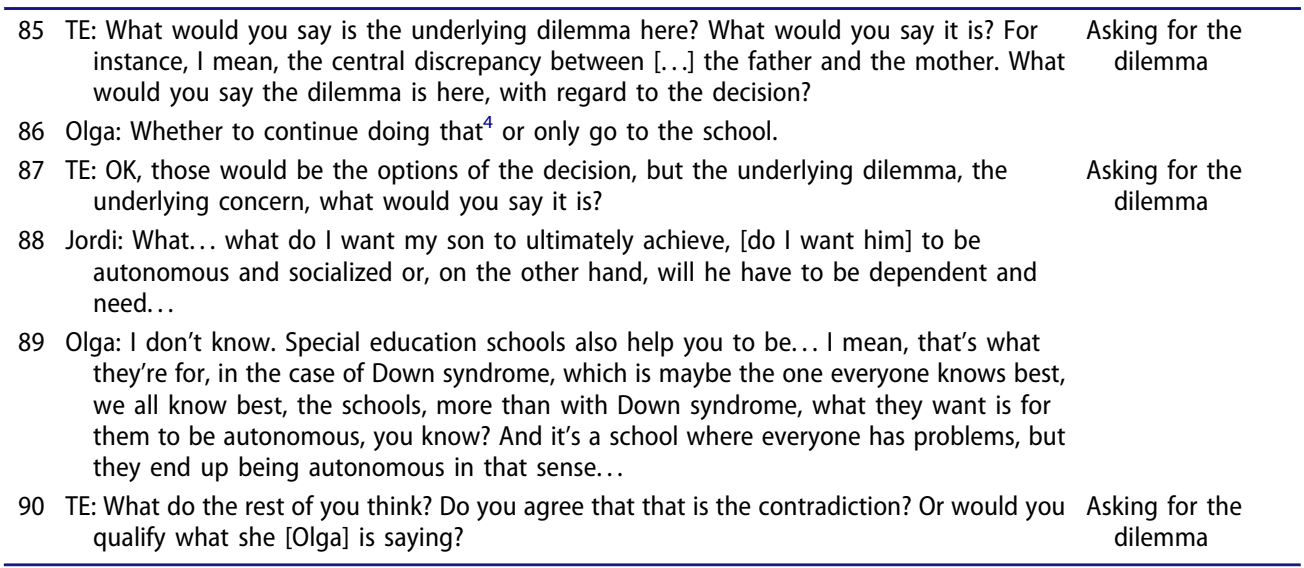

The TE asked for the dilemma in 85, and Olga made an attempt to define it. The TE then drew a distinction between the various possible alternatives and the dilemma, and in 88 Jordi offered a definition of the dilemma that was more similar to the kind of definition provided by the TE in his previous modelling. However, in 89, Olga questioned whether Jordi's definition really was the dilemma in this situation. In 90, the TE opened the conversation about whether or not the dilemma proposed by Jordi really was the dilemma in this situation. Note that the TE seemed to agree with the terms in which Jordi proposed the dilemma, insofar as it was not a choice between specific opposing decisions, but rather a conflict of aims. Since, in the TE's view, a dilemma had been proposed in the proper terms, his concern shifted to trying to elaborate and improve the definition of the dilemma proposed by the preservice teachers. He did so basically by means of a strategy here called 
problematizing, which consist of noting incoherencies and problems in the definition of the dilemma(s) provided by the preservice teachers. Consider, for example, the following excerpt:

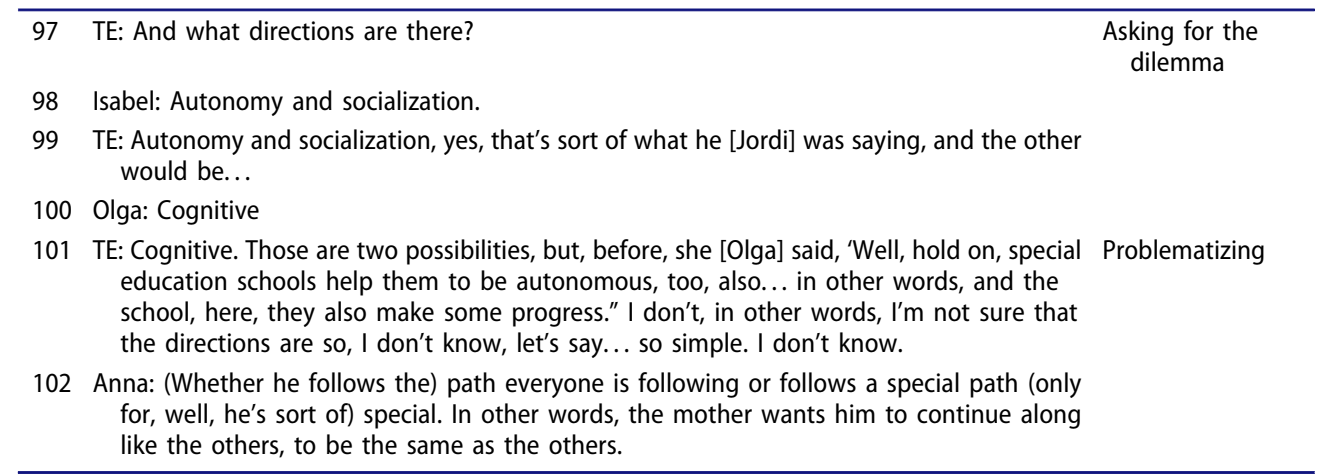

Here, the TE asked for the dilemma again, and the dilemma previously proposed by Jordi re-emerged in the words of Isabel and Olga: autonomy/socialization vs cognitive improvement. The TE then problematized this definition of the dilemma, using Olga's previous perspective, leading Anna to propose an alternative definition of the dilemma: everybody's path vs. a special path. The discussion continued for several turns, but the TE seemed to have gotten to where he wanted, because after a few more turns he offered his modelling and assumed the dilemma as defined by Anna.

\section{Discussion}

In this paper, we have presented a case study on 5 weekly sessions of collaborative reflection involving one teacher educator and 14 preservice teachers. Our aim was to understand how certain educational supports facilitated pre-service teachers' learning to reflect within a collaborative setting. In this case, the purpose of the collaborative reflection was to explain various situations in terms of the tensions or dilemmas which lay in the depth of these situations. This is in line with the reflection processes reported, for example, by Yoon and Kim (2009), Saiz-Linares and Susinos-Rada (2018) or Behizadeh, Thomas, and Cross (2017). In this case, the data showed a sharp change in the trend of the preservice teachers' reflection after Session 2: in the first two sessions, the reflection was very much focused on trying to provide alternative actions to solve the situations; after Session 2, there was a sharp decrease in action-focused reflection and a clear increase in explanation-focused reflection. This evolution was consistent with the objectives pursued by the teacher educator. Therefore, in this case, the participants seemed to show progress in how they reflected.

The educational support provided seems to have played a significant role in facilitating this progress in the preservice teachers' reflection. Based on the results presented here, this support can be described on two related levels: the social organization of collaborative reflection and the teacher educator's assistance. In terms of the social organization of the reflection, a consistent sequence of four phases was identified in this case: Clarification, 
Exploration, Focalization, and Interpretation. Beyond the specificity of these phases, it is interesting to note that two related trends can be appreciated in this sequence. On the one hand, there is a progression from analysis to synthesis; on the other hand there is a progression from open facilitation to directive facilitation. Thus, clarification and exploration are mainly devoted to the free expression of the different views by the student teachers (analysis). This is promoted by a very open style of facilitation with limited intervention of the teacher educator. Focalization and Interpretation are dedicated to putting the different views together, and making them interact in an integrated system (synthesis). In these phases, the facilitation style is progressively more directive, with increasing intervention by the teacher educator. This is consistent with the findings reported by Kim and Silver (2016) on the one hand, and also with the proposal of Gelfuso (2016) on the other. Interestingly, our results suggest that both trends are intrinsically related in collaborative reflection: for the emergence of different views on the situation (analysis), open facilitation is necessary; for promoting the interrelation between these views, progressing to more directive facilitation seems to be crucial. The observed relationship between these two trends is in consonance with the findings by Liu (2017).

In terms of the teacher educator's assistance, six main strategies have been identified and described. As showed in the Table 3 above, these six strategies can be framed within two criteria. Firstly, they can be framed regarding the aims pursued by the teacher educator in each moment of the reflection process, according to the contingent necessities of the student teachers during the process. Thus, in the first two sessions, when the preservice teachers' reflection focused on alternative actions to solve the situation, the teacher educator seemed to be primarily concerned with promoting an explanatory stance. He did so by trying to balance and re-focus the preservice teachers' views using framing and oppositional voice strategies, and trying to facilitate the identification of dilemmas by means of the strategy of counterpoising alternatives. At the end of the second session, and contingently with the sharp change in the preservice teachers' reflection (from action to explanation) that took place at this point, there was a shift in the teacher educator's assistance, which came to focus more on the quality and richness of the explanations provided by the student teachers. From that point on, the teacher educator's assistance stressed the strategies of asking for the dilemma, problematizing, and modelling.

Secondly, the six strategies can be framed according to the twofold dynamic analysissynthesis and open facilitation-directive facilitation. Thus, framing and oppositional voice permitted to hold the presence of multiple views in conversation, especially when student teachers tried to eliminate views to avoid dilemmas (Liu 2017). These strategies can be considered ways of relatively open facilitation, since they do not push reflection to a given direction but just maintain the balance and plurality of views of the conversation. Counterpoising alternatives, asking for the dilemma, problematizing and modelling pushed the interrelation between the multiple views. Although they have different degrees of directedness, these three strategies can be considered as forms of more directive facilitation, in the sense that they push students' reflection to one specific direction.

The findings presented here must be taken with caution. First, because they are the results of a case study, they must be considered together and compared with other findings in the field and cannot be directly generalized. Second, because the reflection process studied in this case had a very specific goal (i.e., to delve deeper into the 


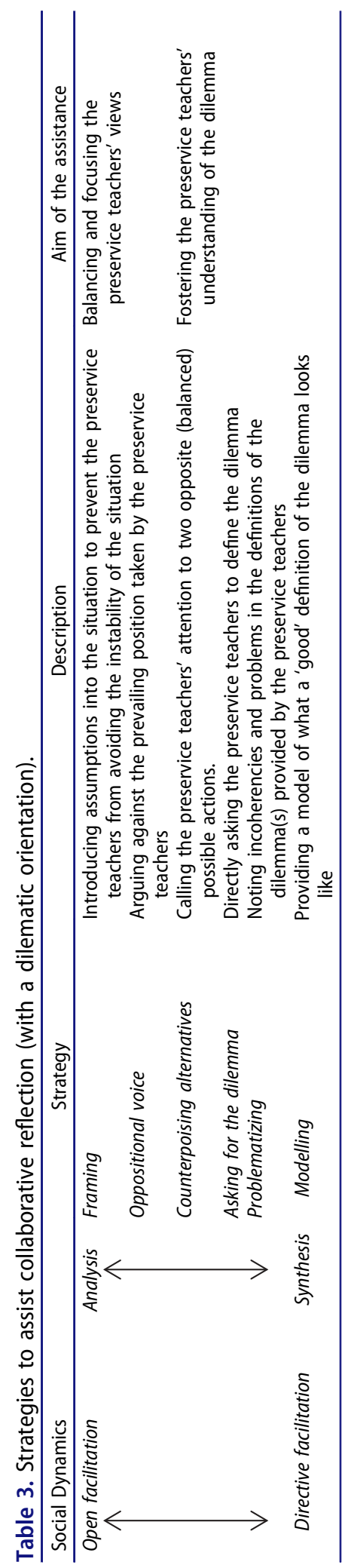


dilemmas of the situation), the results may not be informative for reflection processes with other goals. Bearing these cautions in mind, the results of this study may help to better understand the social dynamics of successful collaborative reflection, and may help teacher educators to navigate and promote this dynamics by means of the six strategies of facilitation identified and described in this paper.

\section{Notes}

1. Dewey wrote two versions of 'How we think', one published in 1910 and the other in 1933. The two versions present important differences. The transition from analysis to synthesis is central in the 1910 version; in the 1933 this issue loses importance, but it is still considered.

2. The situation $C$ can be described as follows: In the last year of primary school there is a student with substantial learning difficulties; the teachers decide to pass her, allowing her to go on to secondary school.

3. Situation $D$ can be described as follows: The mother of a child with autism spectrum disorder does not want him to combine ordinary school with a special school; the father disagrees (the parents are divorced).

4. Here, 'doing that' refers the child's attendance of both ordinary and special schools (see Table 1).

\section{Acknowledgments}

This work was supported by the Spanish 'Ministerio de Economia y Competitividad' [grant EDU201344632-P]. We are deeply grateful to all the preservice teachers who participated in this research.

\section{Disclosure statement}

No potential conflict of interest was reported by the authors.

\section{Funding}

This work was supported by the Ministerio de Economía y Competitividad [EDU2013-44632-P].

\section{Notes on contributors}

Marc Clarà (PhD in Psychology) is a Serra Húnter Fellow at the University of Lleida. His research interests include teachers' reflection, teachers' emotion and decision making, and dialogic educational interaction, especially collective inquiry. Currently he is the Principal Investigator of the NARRES project (funded by the Ministry of Economy and Business of Spain), which investigates the narrative mediation of teachers' emotion.

Teresa Mauri (PhD in Psychology) is a teacher and Professor at the University of Barcelona. She has researched, promoted and co-directed works on the development of the school curriculum, the analysis of the interaction processes in educational situations, learning assessment and innovation, teaching and evaluation in Higher Education and specifically in the practicum period of primary teachers-to-be. Her current research focuses on two major areas: first, the study of the formation and development of teachers' practical knowledge, based on the analysis of the collaborative reflection between teachers in professional contexts and between tutors and teacher-students in the practicum period; second, evaluation and formative feedback in Higher Education. She 
coordinates the line of research named "Joint activity, knowledge and learning in professional communities: teachers and students learning together and educational communities in development" of the Interuniversity Doctoral Program on Educational Psychology (DIPE)

Rosa Colomina (PhD in Psychology) is a tenured lecturer of Educational Psychology at University of Barcelona. She has participated in several research projects on the study of the mechanisms of educational influence in adult-children interactional situations in family contexts and between teacher and students in formal teaching and learning situations. Her work has focused on issues related to the analysis of joint activity and discourse, in the learning assessment, in the study of the influence of ICT in the construction of knowledge in educational situations. Currently, her research focuses on the study of reflection processes on practice situations for the improvement of teacher training.

Javier Onrubia (PhD in Psychology) is a Tenured Lecturer at the Universitat de Barcelona. His research has focused on studying processes of educational assistance, from a sociocultural perspective. In recent years, he has studied these processes in three particular kinds of situations: computer-supported collaborative learning, collaborative school consultation, and student teachers joint reflection on teaching practice. He has been also focused on teaching innovation activities at the University level. He has also developed numerous activities of continuous training addressed to primary and secondary teachers and to school psychologists.

\section{References}

Alles, M., T. Seidel, and A. Gröschner. 2018. "Establishing a Positive Learning Atmosphere and Conversation Culture in the Context of a Video-Based Teacher Learning Community." Professional Development in Education (Advance online publication). doi:10.1080/19415257.2018.1430049.

Attard, K. 2012. "Public Reflection within Learning Communities: An Incessant Type of Professional Development." European Journal of Teacher Education 35 (2): 199-211. doi:10.1080/ 02619768.2011 .643397$.

Beauchamp, C. 2015. "Reflection in Teacher Education: Issues Emerging from a Review of Current Literature." Reflective Practice 16 (1): 123-141. doi:10.1080/14623943.2014.982525.

Behizadeh, N., C. Thomas, and S. B. Cross. 2017. "Reframing for Social Justice: The Influence of Critical Friendship Groups on Preservice Teachers' Reflective Practice." Journal of Teacher Education (Advance online publication). doi:10.1177/0022487117737306.

Blomberg, G., M. G. Sherin, A. Renkl, I. Glogger, and T. Seidel. 2014. "Understanding Video as a Tool for Teacher Education: Investigating Instructional Strategies to Promote Reflection." Instructional Science 42: 443-463. doi:10.1007/S11251-013-9281-6.

Buschor, C. B., and E. Kamm. 2015. "Supporting Student Teachers' Reflective Attitude and Research-Oriented Stance." Educational Research for Policy and Practice 14: 231-245. doi:10.1007/S10671-015-9186-Z.

Clarà, M. 2015. "What Is Reflection? Looking for Clarity in an Ambiguous Notion." Journal of Teacher Education 66: 261-271. doi:10.1177/0022487114552028.

Cochran-Smith, M., and K. Demers. 2010. "Research and Teacher Learning: Taking an Inquiry Stance." In Teachers as Learners, edited by O. Kwo, 13-43. Dordrecht: Springer.

Coll, C., J. Onrubia, and T. Mauri. 2008. "Ayudar a Aprender en Contextos Educativos: El Ejercicio de la Influencia Educativa y el Análisis de la Enseñanza." Revista de Educación 346: 33-70.

Collin, S., T. Karsenti, and V. Komis. 2013. "Reflective Practice in Initial Teacher Training: Critiques and Perspectives." Reflective Practice 14 (1): 104-117. doi:10.1080/14623943.2012.732935.

Daniel, G. R., G. Auhl, and W. Hastings. 2013. "Collaborative Feedback and Reflection for Professional Growth: Preparing First-Year Pre-Service Teachers for Participation in the Community of Practice." Asia-Pacific Journal of Teacher Education 41 (2): 159-172. doi:10.1080/ 1359866X.2013.777025.

Dewey, J. [1910] 1978. "How We Think." In The Middle Works of John Dewey, Volume 6: 1910-1911, edited by J. A. Boydston, 177-356. Carbondale: Southern Illinois University Press. 
Erickson, F., and J. Schulz. 1997. "When Is a Context? Some Issues and Methods in the Analysis of Social Competence." In Mind, Culture and Activity. Seminal Papers from the Laboratory of Comparative Human Cognition, edited by M. Cole, Y. Engeström, and O. Vasquez, 22-31. Cambridge, UK: Cambridge University Press.

Foong, L. Y. Y., M. B. M. N. Nor, and A. Nolan. 2018. "The Influence of Practicum Supervisors' Facilitation Styles on Student Teachers' Reflective Thinking during Collective Reflection." Reflective Practice (Advance online publication). doi:10.1080/14623943.2018.1437406.

Gelfuso, A. 2016. "A Framework for Facilitating Video-Mediated Reflection: Supporting Preservice Teachers as They Create "Warranted Assertabilities" about Literacy Teaching and Learning." Teaching and Teacher Education 58: 68-79. doi:10.1016/j.tate.2016.04.003.

Gelfuso, A., and D. V. Dennis. 2014. "Getting Reflection off the Page: The Challenges of Developing Support Structures for Pre-Service Teacher Reflection." Teaching and Teacher Education 38: 1-11. doi:10.1016/j.tate.2013.10.012.

Harford, J., and G. MacRuairc. 2008. "Engaging Student Teachers in Meaningful Reflective Practice." Teaching and Teacher Education 24: 1884-1892. doi:10.1016/j.tate.2008.02.010.

Jarvis, J., C. Dickerson, K. Thomas, and S. Graham. 2014. "The Action-Reflection-Modeling (ARM) Pedagogical Approach for Teacher Education: A Malaysia-UK Project." Australian Journal of Teacher Education 39 (3): 89-118. doi:10.14221/Ajte.2014v39n3.2.

Killeavy, M., and A. Moloney. 2010. "Reflection in a Social Space: Can Blogging Support Reflective Practice for Beginning Teachers?" Teaching and Teacher Education 26: 1070-1076. doi:10.1016/j. tate.2009.11.002.

Kim, Y., and R. E. Silver. 2016. "Provoking Reflective Thinking in Post Observation Conversations." Journal of Teacher Education 67 (3): 203-219. doi:10.1177/0022487116637120.

Korthagen, F. A. J. 2001. Linking Practice and Theory: The Pedagogy of Realistic Teacher Education. Mahwah, NJ: Lawrence Erlbaum.

Krippendorff, K. 1980. Content Analysis. An Introduction to Its Methodology. Beverly Hills: Sage.

Lampert, M. 1985. "How Do Teachers Manage to Teach? Perspectives on Problems in Practice." Harvard Educational Review 55 (2): 178-194. doi:10.17763/haer.55.2.56142234616x4352.

Land, C. L. 2018. "Examples of c/Critical Coaching: An Analysis of Conversation between Cooperating and Preservice Teachers." Journal of Teacher Education 69 (5): 493-507. doi:10.1177/0022487118761347.

Liu, K. 2015. "Critical Reflection as a Framework for Transformative Learning in Teacher Education." Educational Review 67 (2): 135-157. doi:10.1080/00131911.2013.839546.

Liu, K. 2017. "Creating a Dialogic Space for Prospective Teacher Critical Reflection and Transformative Learning." Reflective Practice. doi:10.1080/14623943.2017.1361919.

Manouchehri, A. 2002. "Developing Teaching Knowledge through Peer Discourse." Teaching and Teacher Education 18: 715-737. doi:10.1016/S0742-051X(02)00030-6.

Mansvelder-Longayroux, D. D., D. Beijaard, and N. Verloop. 2007. "The Portfolio as a Tool for Stimulating Reflection by Student Teachers." Teaching and Teacher Education 23: 47-62. doi:10.1016/j.tate.2006.04.033.

McCullagh, J. F. 2012. "How Can Video Supported Reflection Enhance Teachers' Professional Development?" Cultural Studies of Science Education 7: 137-152. doi:10.1007/S11422-012-9396-0.

Mena-Marcos, J., E. Sanchez, and H. H. Tillema. 2011. "Promoting Teacher Reflection: What Is Said to Be Done." Journal of Education for Teaching: International Research and Pedagogy 37 (1): 21-36. doi:10.1080/02607476.2011.538269.

Moore-Russo, D. A., and J. N. Wilsey. 2014. "Delving into the Meaning of Productive Reflection: A Study of Future Teachers' Reflections on Representations of Teaching." Teaching and Teacher Education 37: 76-90. doi:10.1016/j.tate.2013.10.002.

Postholm, M. B. 2008. "Teachers Developing Practice: Reflection as Key Activity." Teaching and Teacher Education 24: 1717-1728. doi:10.1016/j.tate.2008.02.024.

Saiz-Linares, A., and T. Susinos-Rada. 2018. "El Practicum o Cómo Aprender a través de la Reflexión Colaborativa. El Caso del Problema de Elena." Profesorado 22 (1): 393-411. 
Sorensen, P. 2014. "Collaboration, Dialogue and Expansive Learning: The Use of Paired and Multiple Placements in the School Practicum." Teaching and Teacher Education 44: 128-137. doi:10.1016/j.tate.2014.08.010.

Strauss, A., and J. Corbin. 1990. Basics of Qualitative Research: Grounded Theory Procedures and Techniques. Newbury Park, CA: Sage Publications.

Tigelaar, D. E. H., D. H. J. M. Dolmans, P. C. Meijer, W. S. De Grave, and C. P. M. Van der Vleuten. 2008. "Teachers' Interactions and Their Collaborative Reflection Processes during Peer Meetings." Advances in Health Sciences Education 13: 289-308. doi:10.1007/S10459-006-9040-4.

Tillema, H., and G. J. Van der Westhuizen. 2006. "Knowledge Construction in Collaborative Enquiry among Teachers." Teachers and Teaching: Theory and Practice 12 (1): 51-67. doi:10.1080/ 13450600500365403.

Wopereis, I. G. J. H., P. B. Sloep, and S. H. Poortman. 2010. "Weblogs as Instruments for Reflection on Action in Teacher Education." Interactive Learning Environments 18 (3): 245-261. doi:10.1080/ 10494820.2010.500530.

Yoon, H.-G., and M. Kim. 2009. "Collaborative Reflection through Dilemma Cases of Science Practical Work during Practicum." International Journal of Science Education 32 (3): 283-301. doi:10.1080/09500690802516538. 